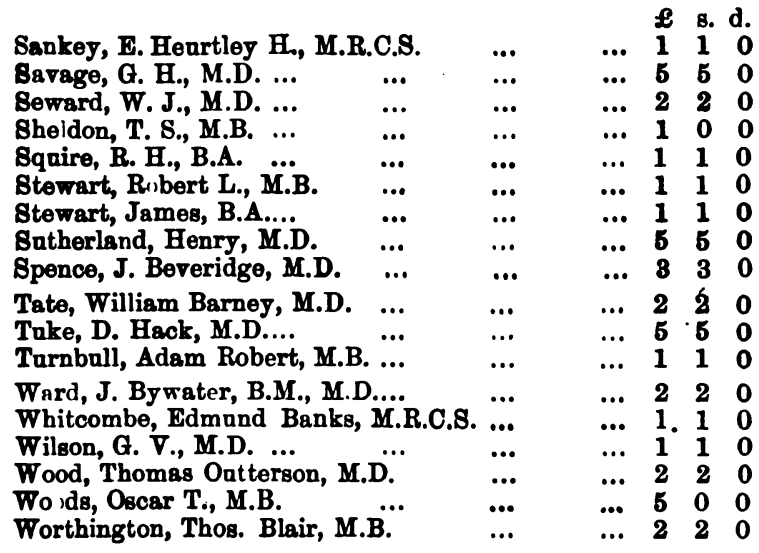

\title{
CERTIFICATE OF EFFICIENCY IN PSYCHOLOGICAL MEDICDNE.
}

We are glad to be able to announce that there is every reason to believe that the recently instituted examination for this certificate having become more widely known, there will in future be a large number of candidates for it in England, Scotland, and Ireland. That its possession will be a great advantage to any young man seeking a lunacy appointment is self-evident. It is also obvious that it will be of use to the public as affording some guarantee of the fitness of - practitioner to deal with mental cases, and to sign medical certificates.

Of the first examination, which was held at Bethlem Hospital, the following reoord appears in the "British Medical Journal," Deo. 4th, 1886 :-

$$
\text { "Certificates in Psychological Medicine. }
$$

"The following is a list of the candidates who have passed the examination for the certificate of efficiency in Psychological Medicine, held at Bethlem Royal Hospital, November 29th and 30th:

" Percy Smith, M.D., Bethlem Royal Hospital.

"Thomas B. Hyslop, M.B., Bethlem Royal Hospital.

“G. M. Robertson, M.B., Edinburgh.

"James Neil, M.D., Warneford House, Oxford.

"Alan Rigden, M.B., County Asylum, near Shrewsbury.

"Walter Pearce, M.D., Maidenhead.

“J. Walter Scott, M.R.C.S., Fareham, Hants.

“ G. D. Symes, M.R.C.S., Dorchester.

“This Examination has been instituted by the Medico.Psychological Association of Great Britain and Ireland, and demands a practical as well as a theoretical knowledge of mental disorders. It consists of a written and oral examination, including the certifying of an insane patient, and occupies a portion of two days. Candidates must be registered medical men, who have resided in an asylum, holding the office of clinical clerk, or as assistant medical officer, for at least three months, or have attended a course of lectures on insanity and the practice of an asylum (where there is clinical teaching) for a like period, or they must give such proofs of experience in lunacy as shall, in the opinion of the President, be sufficient. The following are the written questions, at the recent examination conducted by Dr. G. H. Savage and Dr. D. Hack Tuke : 
"1. Enumerate various methods of classification of mental disorders which have been proposed, and discuss their merits, specifying that method and the forms it comprises which you prefer.

“ 2. What are the symptoms and previous history of an insane patient which would lead you to give an unfavourable prognosis?

" 3 . What forms of mental disorder are most frequently associated with opilepsy, and what do you understand by masked or larvated epilepsy?

“4. What are the questions you would especially ask, if treating a man's teotamentary capacity? What would lead you to suppose him to posseses this capacity, although his mind might not be sound on all points ?

" 5. What treatment would you adopt in a case of acute delirious mania ?

“6. Mention the statutory forms required for the admission of a private patient into an English or Scotch asylum, and the conditions attaching to them."

An examination for the same certificate was held at the Royal Edinbargh Asylum on the 10th and 11th Dec., Drs. Clouston and Rutherford being the examiners.

The following were the questions at the written examination (it not being necessary to answer more than four):-

1. Give the Chief Diagnostic Points, Bodily and Mental, in a case of General Paralysis; and state the Pathological and Physiological reasons why such symptoms should occur in this disease.

2. A case, A. B., female, æt. 34, married, five children, youngest six months old, being nursed, father insane, had the following as her chief symptoms:Headaches, sense of weariness, loss of flesh, anæmia, flashes of light before her eyes, and irritability at first ; those symptoms being followed by mental depression, loss of interest in family, spurts of uncontrollable excitement, sleepleseness, loss of appetite, and suicidal tendencies. Give-1. Classification according to different systems; 2. Prognosis ; and 3. Treatment.

3. Define shortly the terms "Mental Exaltation," "Mental Enfeeblement," and "Insane Delusion," as commonly used by writers on Mental Disease.

4. What are the chief points to be considered in determining the question whether a patient is a "proper person to be detained under care and treatment," and to be observed in granting the statutory Certificate for admission into an Asylum? Criticise and correct the accompanying faulty Certificate.

5. In what forms of mental disease are serious crimes most apt to ocour? What considerations would you give most weight to in determining the question of legal responsibility?

6. Under what circumstances is forcible feeding sometimes necessary? Describe the methods usually adopted, and mention the foods commonly used.

The following gentlemen passed the examination to the satisfaotion of the examiners:-

John Macpherson, M.B., Asoistant Physician, Morningside.

Robert Howden, M.B., Clinical Assistant, Morningside.

Thomas Fraser, M.B., Assistant Physician, Crichton Royal Institution.

John Cram, M.B., Assistant Mledical Officer, Larbert Asylum.

Henry B. Melville, M.B., Assistant Physician, Crichton Roysl Institution. Reference has been made in a furmer number of this Journal (Oct., 1886) to

"The Gaskell Memorial Fund," and its intended application to a prize in an Honours examination, in addition to the pass examination for the certificate above mentioned, which the candidate must have passed before being eligible to compete. This fund is about to be placed at the disposal of the YedicoPsychological Association, and we expect that the first examination for Honours will take place at the close of the next ordinary examination, which falls in due course in July next.

The general object of the prize is declared to be "For the Advancement of the Practical Knowledge of Mental Disorders and their Treatment."

It will be called "The Gaskell Prize." 
The prize will be restricted to candidates submitting to exsmination in England.

Candidates must be at least 23 years of age, and must produce a certificate from the Superintendent of an asylum for the insane of baving been a qualified medical officer in such asylum for at least two yeurs.

The prize to be offered annually and to be accompanied by a suitable medal.

The prize to be withheld if, in the opinion of the examiners, no candidate's paper reaches a certain measure of excellence, the amount to be either carried forward to increase the prize or prizes next year or added to the capital.

STEWART SCHOLARSHIP IN MENTAL DISEASE.

UNIVERSITY. OF DUBLIN-TRINITY COLLEGE.

At the examination for the above Scholarship, held at Michaelmas last, the successful candidate was-

Goo. Revington, M.B., Assistant Medical Officer, Prestwich Asylum, near Manchester.

\section{Appointments.}

Buuxrr, Alder, M.D., appointed Medical Superintendent of the New York State Asylum for the Insane, vice Dr: Gray.

Fraskr, Tros., M.A., M.B., appointed Assistant Physician to the Crichton Royal Institution, Damfries.

Grant, John, M.B., C.M.Edin., Assistant Medical Officer to the Inverness District Asylum, appointed Assistant Medical Officer to the East Riding Asylum, Beverley, Yorkshire.

HAlx, Brw., M.B.Lond., Second Assistant Medical Officer at Banstead, appointed Superintendent of Brook Villa Asylum, Liverpool.

Kray, JoHN, M.B., Assistant Physician to the Crichton Royal Institution, Dumfries, appointed Superintendent of the Mavisbank Asylum, Edinburgh.

Krnadon, E. C., M.B., C.M.Edin., Assistant Medical Officer to the Colney Hatch Asylum, appointed Assistant House-Surgeon to the General Hospital, Nottingham.

Lich pirrd, Jayrs WM., L.R.C.P.Lond., appointed Junior Assistant Medical Officer to the Hants Connty Asylum.

MruviLLx, H. B., M.B., C.M., appointed Assistant Physician to the Crichton Royal Institation, Dumfries.

Strmart, R. O., appointed Assistant Medical Officer, County Asylum, Loicester.

Several Revievos are left over to the next number for want of room. 